\title{
Chemical Compounds from the Preanal Gland Secretions of the Male Tree Agama (Acanthocercus atricollis) (Fam. Agamidae)
}

\author{
José Martín*, Jesús Ortega, and Pilar López \\ Departamento de Ecología Evolutiva, Museo Nacional de Ciencias Naturales, CSIC, \\ José Gutiérrez Abascal 2, 28006 Madrid, Spain. Fax: 34-91-5 645078. \\ E-mail: Jose.Martin@mncn.csic.es \\ * Author for correspondence and reprint requests \\ Z. Naturforsch. 68c, 253-258 (2013); received September 17, 2012/April 30, 2013
}

Chemical signals have an important role in the reproductive behaviour of many lizards. However, the compounds secreted by their femoral or preanal glands, which may be used as sexual signals, are mainly known for lizard species within the Scleroglossa clade, whereas compounds in secretions of lizards within the Iguania clade are much less studied. Based on mass spectra, obtained by GC-MS, we found 60 lipophilic compounds in preanal gland secretions of the male tree agama (Acanthocercus atricollis) (fam. Agamidae), including steroids (mainly cholesterol, cholest-3-ene, and some of their derivatives), fatty acids ranging between $n-\mathrm{C}_{12}$ and $n-\mathrm{C}_{18}$ (mainly hexadecanoic and octadecenoic acids), ketones from $n-\mathrm{C}_{17}$ to $n-\mathrm{C}_{25}$, and other minor compounds, such as tocopherol, squalene, waxy esters, and furanones. We compare the compounds found with those present in other lizard species and discuss their potential function in social behaviour.

Key words: Steroids, Fatty Acids, Ketones, Lizards

\section{Introduction}

Males of many lizard species have conspicuous femoral or preanal glands that secrete chemical compounds especially during the reproductive season (Alberts, 1993; Weldon et al., 2008). These compounds are important in intraspecific communication (Mason, 1992; Mason and Parker, 2010; Martín and López, 2011) as they may signal the characteristics and health state of a male (López et al., 2006; Martín et al., 2007a; López and Martín, 2012). This information may be used by females to select males (e.g. Martín and López, 2000, 2006a; López et al., 2002, 2003; Olsson et al., 2003; López and Martín, 2005a), or by other males to assess the fighting ability or dominance status of the sender (Aragón et al., 2001; Carazo et al., 2007; Martín et al., 2007b).

Femoral or preanal gland secretions are composed of both lipids and proteins, but some lipophilic compounds seem to be involved in pheromonal communication (Mason, 1992; Martín and López, 2006a, 2010a, 2011). However, the presence and abundance of specific compounds varies widely between species (Weldon et al., 2008), which might be due to phylogenetic or environmental differences (Alberts, 1992; Escobar et al., 2003; Martín and López, 2006b). Most information on the chemical composition of secretions relates to lizard species within the Scleroglossa clade, which are considered to rely mainly on chemical senses (Cooper, 1995). Lipophilic compounds have been described in secretions of European lizards of the family Lacertidae (López and Martín, 2005b, c, 2006, 2009; Martín and López, 2006c, d, 2010b; Gabirot et al., 2008, 2010; Kopena et al., 2009), an African lacertid (Khannoon et al., 2011), an African cordylid (Louw et al., 2007), and an American teid (Martín et al., 2011). In contrast, compounds in secretions of lizards within the Iguania clade have been less studied, probably because these lizards seem to rely more on visual cues, although many species have femoral or preanal glands and are capable of chemosensory conspecific recognition (Mason and Parker, 2010). Lipophilic compounds in gland secretions have been described in an iguanid (Weldon et al., 1990; Alberts et al., 1992a, b) and several South American tropidurids (Escobar et al., 2001, 2003). In agamids, only an old study using thin-layer chromatography (TLC) analysed compounds in preanal gland secretions of the lizard Uromastyx hardwickii, suggesting the presence of fatty acids, triacylglycerols, wax esters, sterols and their esters, and phospholipids (Chauhan, 1986). To understand what determines 
the composition of gland secretions of lizards and which is the role of the compounds in social behaviour, we need more studies that deal with a wider range of lizard species within different taxonomic groups and a larger variety of environmental conditions.

In the present paper, we report the results of an analysis by gas chromatography-mass spectrometry (GC-MS) of the lipophilic fraction of preanal gland secretions of the male blue-headed tree agama (Acanthocercus atricollis) from a Tanzanian population. This is an agamid lizard whose range extends from Ethiopia to the eastern and northern parts of South Africa (Spawls et al., 2002; Wagner et al., 2012). Tree agamas are large (average total length between 20 and $30 \mathrm{~cm}$ ), diurnal, insectivorous, tree-dwelling lizards that are sexually dimorphic in size and colouration (Reaney and Whiting, 2002, 2003). Mature males have a bright blue head and two rows of 10-12 preanal pores each (Spawls et al., 2002). Tree agamas spent most of their time on tree trunks, and only come to the ground to cross to another tree. They are strongly territorial and live in structured colonies with one dominant male, several females, and juveniles (Reaney and Whiting, 2002; Spawls et al., 2002). We hypothesized that compounds secreted by preanal glands might be used to scent mark territories on tree trunks, having a role in social organization of this lizard.

\section{Material and Methods}

We obtained seven adult male tree agamas from a commercial dealer (Euroreptiles, L'Hospitalet, Barcelona, Spain). The lizards had been recently captured in the surroundings of Dodoma (Tanzania) during April 2012. Secretion samples were collected in Madrid immediately after arriving (May 19, 2012). We extracted secretions from preanal glands of male lizards by gently pressing with forceps around the preanal pores, and collected secretions directly with glass vials with glass inserts, which were later closed with Teflonlined stoppers. Vials were stored at $-20{ }^{\circ} \mathrm{C}$ until analyses. We also used the same procedure but without collecting secretion, to obtain blank control vials that were treated in the same manner to compare with the lizards samples, and to be sure of excluding contaminants from the handling procedure and to be able to examine impurities in the solvent.
We analysed samples with a ThermoQuest (Austin, TX, USA) Trace 2000 gas chromatograph fitted with a poly $(5 \%$ diphenylsiloxane/95\% dimethylsiloxane) column (Supelco Equity-5, $30 \mathrm{~m}$ length $\times 0.25 \mathrm{~mm}$ ID, $0.25 \mu \mathrm{m}$ film thickness; Supelco Co., Bellefonte, PA, USA) and a ThermoQuest Trace 2000 mass spectrometer as detector. Sample injections of $2 \mu$ l of each sample dissolved in $2 \mathrm{ml}$ of $n$-hexane (capillary GC grade; Sigma-Aldrich Chemical Co., St. Louis, MO, USA) were performed in the splitless mode using helium as the carrier gas, with injector and detector temperatures at $250{ }^{\circ} \mathrm{C}$ and $280{ }^{\circ} \mathrm{C}$, respectively. The oven temperature program was as follows: $50{ }^{\circ} \mathrm{C}$ isothermal for $3 \mathrm{~min}$, then increased to $300{ }^{\circ} \mathrm{C}$ at a rate of $5{ }^{\circ} \mathrm{C} / \mathrm{min}$, and then isothermal $\left(300{ }^{\circ} \mathrm{C}\right)$ for $15 \mathrm{~min}$. Mass spectral fragments below $m / z=46$ were not recorded. Impurities identified in the solvent and/or the control vial samples are not reported. Initial identification of secretion components was performed by comparison of sample mass spectra with those in the NIST/EPA/NIH (NIST 02) computerized mass spectral library. When possible, identifications were confirmed by comparison of spectra and retention times with those of authentic standards (from Sigma-Aldrich). The relative amount of each compound was determined as the percentage of the total ion current (TIC) using the Qual Browser module of the Xcalibur 1.2 software (Thermo Electron Finnigan Co., Austin, TX, USA).

\section{Results}

A total of 60 lipophilic compounds were identified in the preanal gland secretions of male A. atricollis (Table I). The main components were 34 steroids $(66.9 \%$ of TIC), eight fatty acids ranged between $n-\mathrm{C}_{12}$ and $n-\mathrm{C}_{18}(17.7 \%)$, six ketones ranged between $n-\mathrm{C}_{17}$ and $n-\mathrm{C}_{25}(6.4 \%)$, two forms of tocopherol $(2.8 \%)$, six waxy esters $(2.8 \%)$, squalene $(2.6 \%)$, and three furanones $(0.5 \%)$. Major compounds were detected in all individuals, although relative proportions of some compounds showed interindividual variability. On average, the two most abundant compounds were cholesterol (14.4\% of TIC) and hexadecanoic acid $(10.7 \%)$, followed by unidentified derivatives of cholest-3-ene $(7.7 \%)$ and cholest-4-en-3-one $(6.1 \%)$, respectively. 
Table I. Lipophilic compounds found in preanal gland secretions of adult male tree agamas (Acanthocercus atricollis) $(n=7)$. The relative content of each compound was determined as the percentage of the total ion current (TIC) and is reported as the average $( \pm 1 \mathrm{~S})$. Characteristic ions $(\mathrm{m} / \mathrm{z})$ are reported for some unidentified compounds. An asterisk denotes those compounds that were confirmed with authentic standards.

\begin{tabular}{|c|c|c|c|c|c|}
\hline $\begin{array}{l}\mathrm{RT}^{\mathrm{a}} \\
{[\mathrm{min}]}\end{array}$ & Compound & $\begin{array}{l}\text { Content }(\%) \\
(\text { mean } \pm 1 S)\end{array}$ & $\begin{array}{l}\mathrm{RT}^{\mathrm{a}} \\
{[\mathrm{min}]}\end{array}$ & Compound & $\begin{array}{l}\text { Content }(\%) \\
(\text { mean } \pm 1 S)\end{array}$ \\
\hline 25.3 & Dodecanoic acid & $0.12 \pm 0.13^{*}$ & 51.6 & Campesterol & $0.79 \pm 0.49 *$ \\
\hline 29.1 & Tetradecanoic acid & $1.10 \pm 0.51 *$ & 51.7 & Cholest-4-en-3-one & $6.14 \pm 2.38^{*}$ \\
\hline 31.0 & Pentadecanoic acid & $0.12 \pm 0.10^{*}$ & 52.0 & Cholestan-3-one, methyl & $0.48 \pm 0.25$ \\
\hline 31.2 & 2-Heptadecanone & $0.31 \pm 0.24 *$ & & derivative (?) & \\
\hline 32.4 & 9-Hexadecenoic acid & $0.26 \pm 0.09 *$ & 52.1 & Cholesta-4,6-dien-3-one & $0.11 \pm 0.16^{*}$ \\
\hline 32.7 & Hexadecanoic acid & $10.71 \pm 2.30 *$ & 52.2 & 5,6-Epoxy-cholestan-3-ol & $5.75 . \pm 2.67$ \\
\hline 34.9 & 2-Nonadecanone & $0.64 \pm 0.34 *$ & 52.5 & Cholestan-3-one, ethyl & $0.81 \pm 1.70$ \\
\hline 35.1 & 5-Dodecyldihydro-2(3H)- & $0.34 \pm 0.12$ & & derivative (?) & \\
\hline 35.8 & $\begin{array}{l}\text { furanone } \\
9.12 \text {-Octadecad }\end{array}$ & & 52.6 & $\begin{array}{l}\text { Unidentified steroid } \\
(191,248,304,330,401)\end{array}$ & $0.49 \pm 0.49$ \\
\hline $\begin{array}{l}55.0 \\
35.9\end{array}$ & 9-Octadecenoic acid & $4.73 \pm 2.59 *$ & 52.7 & Ergost-8(14)-en-3-ol acetate & $0.32 \pm 0.36$ \\
\hline 36.7 & Octadecanoic acid & $0.72 \pm 1.07 *$ & 52.9 & Lanost-8-en-3-ol & $1.35 \pm 1.32 *$ \\
\hline 38.4 & 2-Heneicosanone & $1.63 \pm 1.30 *$ & 53.0 & Cholest-5-en-3-one & $0.52 \pm 0.46^{*}$ \\
\hline 38.7 & $\begin{array}{l}\text { Dihydro-5-tetradecyl-2(3H)- } \\
\text { furanone }\end{array}$ & $0.10 \pm 0.05$ & 53.1 & $\begin{array}{l}\text { Cholestan-3-one, unidentified } \\
\text { derivative? }\end{array}$ & $1.22 \pm 0.69$ \\
\hline 39.9 & 2-Docosanone & $0.18 \pm 0.13^{*}$ & 53.3 & Stigmast-24(28)-en-3-one & $0.19 \pm 0.22 *$ \\
\hline 41.5 & 2-Tricosanone & $3.26 \pm 2.87 *$ & 53.7 & Cholestane-3,6-dione & $4.30 \pm 2.47 *$ \\
\hline 44.4 & 2-Pentacosanone & $0.41 \pm 0.30 *$ & 54.1 & Stigmast-4-en-3-one & $0.97 \pm 0.45^{*}$ \\
\hline 45.0 & Unidentified furanone & $0.11 \pm 0.11$ & 54.6 & Octadecyl hexadecanoate & $0.16 \pm 0.16$ \\
\hline 45.7 & Squalene & $2.62 \pm 1.34 *$ & 55.1 & Stigmastane-3,6-dione & $0.45 \pm 0.41 *$ \\
\hline 46.5 & Cholest-2-ene & $0.09 \pm 0.02 *$ & 56.3 & Octadecyl octadecenoate & $0.51 \pm 1.05 *$ \\
\hline 46.9 & Cholesta-4,6-dien-3-ol & $0.29 \pm 0.09 *$ & 56.5 & Stigmastane-3,6-dione, unidenti- & $0.52 \pm 0.60$ \\
\hline 47.2 & Cholesta-3,5-diene & $0.46 \pm 0.18 *$ & & fied derivative? & \\
\hline 47.6 & $\begin{array}{l}\text { Unidentified steroid } \\
(197,251,350,365)\end{array}$ & $0.07 \pm 0.07$ & 57.2 & $\begin{array}{l}\text { Cholest-3-ene, unidentified } \\
\text { derivative? }\end{array}$ & $2.80 \pm 2.95$ \\
\hline 48.7 & $\gamma$-Tocopherol & $0.05 \pm 0.06^{*}$ & 57.6 & Cholest-3-ene, unidentified & $7.67 \pm 2.72$ \\
\hline 49.8 & $\begin{array}{l}\text { Cholestan-3-ol, unidentified } \\
\text { derivative? }\end{array}$ & $1.84 \pm 1.44$ & 61.8 & $\begin{array}{l}\text { derivative? } \\
\text { Eicosyl hexadecanoate }\end{array}$ & $0.50 \pm 0.64 *$ \\
\hline 50.1 & $\mathrm{D}-\alpha$-Tocopherol & $2.78 \pm 2.78 *$ & 63.1 & Cholest-3-ene, unidentified & $3.16 \pm 6.06$ \\
\hline 50.2 & Cholesterol & $14.40 \pm 8.83^{*}$ & & & \\
\hline 50.4 & Cholestan-3-ol & $2.28 \pm 1.92 *$ & 65.5 & Cholest-3-ene, unidentified & $0.27 \pm 0.48$ \\
\hline 50.5 & Cholest-8(14)-en-3-ol & $2.01 \pm 1.35^{*}$ & 665 & & 29 \\
\hline 50.7 & Cholestan-3-one & $3.83 \pm 1.97 *$ & 66.5 & $\begin{array}{l}\text { Hexadecanoic acid } \\
1,5 \text {-pentanediyl ester }\end{array}$ & 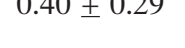 \\
\hline 50.8 & Cholest-7-en-3-one & $0.75 \pm 0.58 *$ & 66.8 & Octadecenyl hexadecenoate & $0.52 \pm 1.17 *$ \\
\hline 51.2 & $\begin{array}{l}\text { Unidentified steroid } \\
(233,274,382,400,415)\end{array}$ & $0.56 \pm 0.57$ & $\begin{array}{l}00.0 \\
67.3\end{array}$ & $\begin{array}{l}\text { Cholest-3-ene, unidentified } \\
\text { derivative }\end{array}$ & $0.73 \pm 1.07$ \\
\hline 51.3 & $\begin{array}{l}\text { Unidentified steroid } \\
(175,248,356,398)\end{array}$ & $0.86 \pm 0.66$ & 67.8 & Octadecyl octadecanoate & $0.66 \pm 1.43^{*}$ \\
\hline
\end{tabular}

$51.4 \quad$ Unidentified steroid $(229,346,382,397)$

\section{Discussion}

Preanal secretions of tree agama lizards contain a very high portion of steroids and fatty acids, with cholesterol and hexadecanoic acid being the most abundant compounds. Similar types of compounds have been found in secretions of most of other lizard species examined (Weldon et al., 2008). Cholesterol is often found in femoral

gland secretions of most lizards, but the presence and relative abundance of other steroids seems to be a characteristic of each species. In tree agamas the abundance of cholestan-3-one and cholestan3 -ene is notorious, and, presumably, some of their derivatives, which remained unidentified but seemed similar to those found in European "green" lizards of the genus Lacerta (Kopena et al., 2009; Martín and López, 2010b). These ster- 
oids may result from the metabolism of cholesterol, but their identification, origin, and potential role in secretions remain to be investigated.

Similarly, hexadecanoic acid, followed by octadecenoic acid, are the most abundant free fatty acids in secretions of this and other lizards (Weldon et al., 2008). However, in contrast to other lizards from arid regions, there were no fatty acids of higher molecular weight, which could be more stable in scent marks (e.g. López and Martín, 2005b). This suggests that the substrates usually scent marked by tree agamas (i.e. tree trunks) could allow that fatty acids of medium molecular weight persist in scent marks. Also, the large amount of steroids may protect these fatty acids.

The presence of a series of saturated methyl ketones with mostly odd-numbered carbon chains is noteworthy in secretions of tree agamas. A similar bishomologous series of $\mathrm{C}_{17}-\mathrm{C}_{25}$ methyl ketones were found in the femoral gland secretions of the phylogenetically unrelated South African sungazer (Cordylus giganteus, Cordylidae) (Louw et al., 2007) and in the skin of some snakes (Mason et al., 1990; reviewed in Weldon et al., 2008). These methyl ketones were postulated to arise from free fatty acids that have undergone $\beta$-oxidation followed by decarboxylation (Ahern and Downing, 1974). Interestingly, similar ketones from skin glands have a prominent role in the social and sexual behaviour of red garter snakes (Mason et al., 1990), so it would be interesting to test whether ketones might have a similar role in tree agamas.

Ahern D. G. and Downing D. T. (1974), Skin lipids of the Florida indigo snake. Lipids 9, 8-14.

Alberts A. C. (1992), Constraints on the design of chemical communication systems in terrestrial vertebrates. Am. Nat. 139, 62-89.

Alberts A. C. (1993), Chemical and behavioral studies of femoral gland secretions in iguanid lizards. Brain Behav. Evol. 41, 255-260.

Alberts A. C., Sharp T. R., Werner D. I., and Weldon P. J. (1992a), Seasonal variation of lipids in femoral gland secretions of male green iguanas, Iguana iguana. J. Chem. Ecol. 18, 703-712.

Alberts A. C., Pratt N. C., and Phillips J. A. (1992b), Seasonal productivity of lizard femoral glands: Re-
Waxy esters, together with squalene and tocopherol may function as antioxidants of other compounds in secretions and may contribute to the durability of scent marks on the surface of tree trunks. Finally, we did not find any alcohol in secretions of tree agamas, which coincides with the lack of alcohols in secretions of the few Iguanian lizards species analysed, and contrasts with the frequency and abundance of alcohols in lizards within the Scleroglossa clade (see Weldon et al., 2008 for a review).

Further studies are clearly needed to understand the patterns of presence and abundance of different compounds in femoral or preanal gland secretions of lizards, and how phylogenetic relationships and environmental conditions can explain the characteristics of these secretions. Also, we need to clarify the possible role of the compounds found in femoral gland secretions with potential of being signaling pheromones, such as the series of methyl ketones in secretions of tree agamas, in social organization, and sexual selection processes of lizards.

\section{Acknowledgements}

We thank an anonymous reviewer for helpful comments, Euroreptiles for providing lizards, Luis Cuadra and Elena Fernández for technical assistance with chemical analyses, and "El Ventorrillo" MNCN Field Station for use of their facilities. Financial support was provided by the project MICIIN-CGL2011-24150/BOS and by a predoctoral JAE-pre grant to J. O. lationship to social dominance and androgen levels. Physiol. Behav. 51, 729-733.

Aragón P., López P., and Martín J. (2001), Chemosensory discrimination of familiar and unfamiliar conspecifics by lizards: implications of field spatial relationships between males. Behav. Ecol. Sociobiol. 50, 128-133.

Carazo P., Font E., and Desfilis E. (2007), Chemosensory assessment of rival competitive ability and scent mark function in a lizard (Podarcis hispanica). Anim. Behav. 74, 895-902.

Chauhan N. B. (1986), A preliminary report on the lipid components of pre-anal gland secretion of lizards. Hemidactylus flaviviridis and Uromastyx hardwickii. J. Anim. Morphol. Physiol. 33, 73-76. 
Cooper W. E. (1995), Foraging mode, prey chemical discrimination, and phylogeny in lizards. Anim. Behav. 50, 973-985.

Escobar C. A., Labra A., and Niemeyer H. M. (2001), Chemical composition of precloacal secretions of $\mathrm{Li}$ olaemus lizards. J. Chem. Ecol. 27, 1677-1690.

Escobar C. M., Escobar C. A., Labra A., and Niemeyer H. M. (2003), Chemical composition of precloacal secretions of two Liolaemus fabiani populations: are they different? J. Chem. Ecol. 29, 629-638.

Gabirot M., López P., Martín J., de Fraipont M., Heulin B., Sinervo B., and Clobert J. (2008), Chemical composition of femoral secretions of oviparous and viviparous types of male common lizards Lacerta vivipara. Biochem. Syst. Ecol. 36, 539-544.

Gabirot M., Castilla A. M., López P., and Martín J. (2010), Differences in chemical signals may explain species recognition between an island lizard, Podarcis atrata, and related mainland lizards, $P$. hispanica. Biochem. Syst. Ecol. 38, 521-528.

Khannoon E. R., Flachsbarth B., El-Gendy A., Mazik J., Hardege J. D., and Schulz S. (2011), New compounds, sexual differences, and age-related variations in the femoral gland secretions of the lacertid lizard Acanthodactylus boskianus. Biochem. Syst. Ecol. 39, 95-101.

Kopena R., López P., and Martín J. (2009), Lipophilic compounds from the femoral gland secretions of male Hungarian green lizards, Lacerta viridis. Z. Naturforsch. 64c, 434-440.

López P. and Martín J. (2005a), Female Iberian wall lizards prefer male scents that signal a better cellmediated immune response. Biol. Lett. 1, 404-406.

López P. and Martín J. (2005b), Age related differences in lipophilic compounds found in femoral gland secretions of male spiny-footed lizards, Acanthodactylus erythrurus. Z. Naturforsch. 60c, 915-920.

López P. and Martín J. (2005c), Chemical compounds from femoral gland secretions of male Iberian rock lizards, Lacerta monticola cyreni. Z. Naturforsch. 60c, $632-636$.

López P. and Martín J. (2006), Lipids in the femoral gland secretions of male Schreiber's green lizards, Lacerta schreiberi. Z. Naturforsch. 61c, 763-768.

López P. and Martín J. (2009), Lipids in femoral gland secretions of male lizards, Psammodromus hispanicus. Biochem. Syst. Ecol. 37, 304-307.

López P. and Martín J. (2012), Chemosensory exploration of male scent by female rock lizards result from multiple chemical signals of males. Chem. Sens. 37, 47-54.

López P., Muñoz A., and Martín J. (2002), Symmetry, male dominance and female mate preferences in the Iberian rock lizard, Lacerta monticola. Behav. Ecol. Sociobiol. 52, 342-347.

López P., Aragón P., and Martín J. (2003), Responses of female lizards, Lacerta monticola, to males' chemical cues reflect their mating preference for older males. Behav. Ecol. Sociobiol. 55, 73-79.

López P., Amo L., and Martín J. (2006), Reliable signaling by chemical cues of male traits and health state in male lizards, Lacerta monticola. J. Chem. Ecol. 32, $473-488$.
Louw S., Burger B. V., Le Roux M., and Van Wyk J. H. (2007), Lizard epidermal gland secretions I: chemical characterization of the femoral gland secretion of the sungazer, Cordylus giganteus. J. Chem. Ecol. 33, $1806-1818$.

Martín J. and López P. (2000), Chemoreception, symmetry and mate choice in lizards. Proc. R. Soc. London B 267, 1265-1269.

Martín J. and López P. (2006a), Links between male quality, male chemical signals, and female mate choice in Iberian rock lizards. Funct. Ecol. 20, 1087-1096.

Martín J. and López P. (2006b), Interpopulational differences in chemical composition and chemosensory recognition of femoral gland secretions of male lizards Podarcis hispanica: implications for sexual isolation in a species complex. Chemoecology 16, 31-38.

Martín J. and López P. (2006c), Age-related variation in lipophilic chemical compounds from femoral gland secretions of male lizards Psammodromus algirus. Biochem. Syst. Ecol. 34, 691-697.

Martín J. and López P. (2006d), Vitamin D supplementation increases the attractiveness of males' scent for female Iberian rock lizards. Proc. R. Soc. London B 273, 2619-2624.

Martín J. and López P. (2010a), Condition-dependent pheromone signalling by male rock lizards: more oily scents are more attractive. Chem. Sens. 35, 253-262.

Martín J. and López P. (2010b), Multimodal sexual signals in male ocellated lizards Lacerta lepida: vitamin $\mathrm{E}$ in scent and green coloration may signal male quality in different sensory channels. Naturwissenchaften 97, 545-553.

Martín J. and López P. (2011), Pheromones and reproduction in reptiles. In: Hormones and Reproduction of Vertebrates, Vol. 3, Reptiles (Norris D. O. and Lopez K. H., eds.). Academic Press, San Diego, CA, USA, pp. 141-167.

Martín J., Civantos E., Amo L., and López P. (2007a), Chemical ornaments of male lizards Psammodromus algirus may reveal their parasite load and health state to females. Behav. Ecol. Sociobiol. 62, 173-179.

Martín J., Moreira P. L., and López P. (2007b), Statussignalling chemical badges in male Iberian rock lizards. Funct. Ecol. 21, 568-576.

Martín J., Chamut S., Manes M. E., and López P. (2011), Chemical constituents of the femoral gland secretions of male tegu lizards (Tupinambis merianae) (fam. Teiidae). Z. Naturforsch. 66c, 434-440.

Mason R. T. (1992), Reptilian pheromones. In: Biology of the Reptilia, Vol. 18 (Gans C. and Crews D., eds.). University of Chicago Press, Chicago, USA, pp. 114-228.

Mason R. T. and Parker M. R. (2010), Social behavior and pheromonal communication in reptiles. J. Comp. Physiol. A 196, 729-749.

Mason R. T., Jones T. H., Fales H. M., Pannell L. K., and Crews D. (1990), Characterization, synthesis, and behavioral response to sex pheromone in garter snakes. J. Chem. Ecol. 16, 2353-2369.

Olsson M., Madsen T., Nordby J., Wapstra E., Ujvari B., and Wittsell H. (2003), Major histocompatibility complex and mate choice in sand lizards. Proc. R. Soc. London B (Suppl.) 270, 254-256. 
Reaney L. T. and Whiting M. J. (2002), Life on a limb: ecology of the tree agama (Acanthocercus a. atricollis) in southern Africa. J. Zool. 257, 439-448.

Reaney L. T. and Whiting M. J. (2003), Picking a tree: habitat use by the tree agama, Acanthocercus atricollis atricollis, in South Africa. Afr. Zool. 38, 273-278.

Spawls S., Howell K. M., Drewes R., and Ashe J. (2002), A Field Guide to the Reptiles of East Africa. Academic Press, London, UK.

Wagner P., Greenbaum E., and Bauer A. (2012), A new species of the Acanthocercus atricollis complex
(Squamata: Agamidae) from Zambia. Salamandra 48, $21-30$.

Weldon P. J., Dunn B. S., McDaniel C. A., and Werner D. I. (1990), Lipids in the femoral gland secretions of the green iguana (Iguana iguana). Comp. Biochem. Physiol. B 95, 541-543.

Weldon P. J., Flachsbarth B., and Schulz S. (2008), Natural products from the integument of nonavian reptiles. Nat. Prod. Rep. 25, 738-756. 